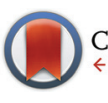

CrossMark \& click for updates

Cite this: Food Funct., 2016, 7, 2692

Received 29th January 2016,

Accepted 6th May 2016

DOI: $10.1039 / c 6 f o 00122 j$

www.rsc.org/foodfunction

\section{Grape powder attenuates the negative effects of GLP-1 receptor antagonism by exendin-3 (9-39) in a normoglycemic mouse model $\dagger$}

\author{
T. C. Haufe, ${ }^{a}$ A. D. Gilley, ${ }^{a}$ K. M. Goodrich, ${ }^{a}$ C. M. Ryan, ${ }^{a}$ A. T. Smithson, ${ }^{a}$ \\ M. W. Hulver, ${ }^{b, c}$ D. Liu ${ }^{b}$ and A. P. Neilson*a
}

Prediabetes is a condition affecting $35 \%$ of US adults and about $50 \%$ of US adults age $65+$. Foods rich in polyphenols, including flavanols and other flavonoids, have been studied for their putative beneficial effects on many different health conditions including type 2 diabetes mellitus and prediabetes. Studies have shown that some flavanols increase glucagon-like peptide 1 (GLP-1) secretion. GLP-1 is a feeding hormone that increases insulin secretion after carbohydrate consumption, and increased GLP-1 secretion may be responsible for some of the beneficial effects on glycemic control after flavanol consumption. The present study explored the effects of grape powder consumption on metrics of glycemic health in normoglycemic and prediabetic C57BL/6J mice; additionally, the mechanism of action of grape powder polyphenols was investigated. Grape powder significantly reduced $(p<0.01)$ blood glucose levels following oral glucose gavage after GLP-1 receptor antagonism by exendin-3 (9-39) compared to sugarmatched control, indicating that it was able to attenuate the hyperglycemic effects of GLP-1 receptor antagonism. Grape powder was employed in acute (1.6 g grape powder per kg bodyweight) and longterm high fat diet (grape powder incorporated into treatment diets at $5 \% \mathrm{w} / \mathrm{w}$ ) feeding studies in normoglycemic and prediabetic (diet-induced obesity) mice; grape powder did not impove glycemic control in these studies versus sugar-matched control. The mechanisms by which grape powder ameliorates the deleterious effects of GLP-1 receptor antagonism warrant further study.

\section{Introduction}

"Prediabetes" is defined as impaired fasting glucose (IFG) and/ or impaired glucose tolerance (IGT) approaching, but not reaching, clinically diagnosed diabetes. ${ }^{1}$ Roughly $35 \%$ of US adults, and $50 \%$ of those age $65+$, are thought to be prediabetic. ${ }^{2}$ Prediabetes is a major risk factor for diabetes, as $30-70 \%$ of prediabetic individuals eventually progress to type 2 diabetes mellitus (T2DM). ${ }^{3}$ Despite this risk, diet or lifestyle interventions targeting glycemic control can significantly delay or halt progression from prediabetes to T2DM. ${ }^{4}$ Dietary interventions for glycemic control in individuals with prediabetes

\footnotetext{
${ }^{a}$ Department of Food Science and Technology, Virginia Polytechnic Institute and State University, 1981 Kraft Dr., Blacksburg, VA 24060, USA.

E-mail: andrewn@vt.edu; Fax: +1 (540)-231-9293; Tel: +1 (540)-231-8391

${ }^{b}$ Department of Human Nutrition, Foods and Exercise, Virginia Polytechnic Institute and State University, Blacksburg, VA 24060, USA

${ }^{c}$ Metabolic Phenotyping Core Facility, Virginia Polytechnic Institute and State University, Blacksburg, VA, USA

$\dagger$ Electronic supplementary information (ESI) available. See DOI: 10.1039/ c6fo00122j
}

are therefore a potentially viable strategy to reduce incidence of diabetes in this "at-risk" population.

Grapes are rich sources of many potentially anti-diabetic compounds, including the flavan-3-ols (catechins and procyanidins, Fig. 1). ${ }^{5}$ Consumption of grapes and products rich in grape flavan-3-ols reduces weight gain, inhibits development of hyperlipidemia, and improves fasting blood glucose, insulin sensitivity and oral glucose tolerance in animal models of obesity and diabetes. ${ }^{6,7}$ Studies have also shown that consumption of grape products can improve glycemic control. ${ }^{8}$ These systemic improvements to body composition and glucose homeostasis are thought to be due to a variety of mechanisms, including enhanced $\beta$-cell function, ${ }^{9,10}$ improved insulin signaling/sensitivity, ${ }^{11-13}$ and protection of substrate metabolic flexibility in skeletal muscle. ${ }^{14,15}$ However, many of these studies employed some form of grape seed extract, whereas the present research employs grape powder made from lyophilized whole grapes as an experimental substitute for whole grapes. Use of whole grape material, as opposed to extracts, is needed in order to observe the potential beneficial effects after grape consumption, which is more representative of actual dietary patterns. Most studies to date have been pri- 


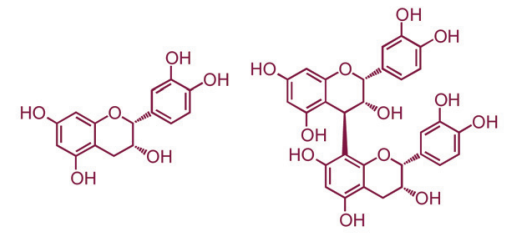

EC monomer

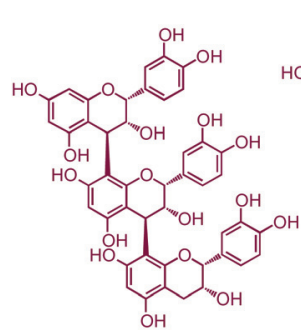

trimer

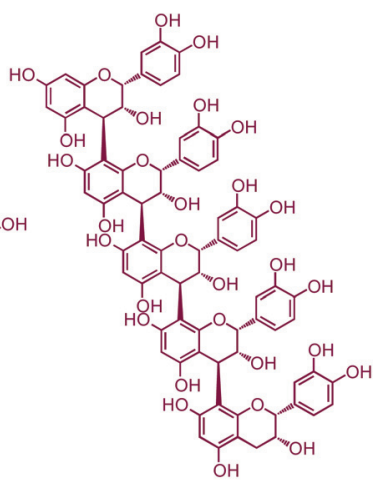

pentamer

Fig. 1 Structures of representative flavan-3-ols found in grapes.

marily descriptive (grapes are fed and endpoints observed), and thus rigorous in vivo mechanistic experiments are still needed to isolate and identify the specific mechanism(s) by which grapes exert their anti-diabetic activities. The lack of a definitive mechanism of action limits the potential for welldesigned human clinical trials with appropriate mechanistic targets and endpoints to study the efficacy of grapes for blood glucose control.

Recent studies suggest that ingested flavan-3-ols (which are found in grapes) act in the gut by modulating secretion and/or degradation of incretin hormones, including glucagon-like peptide 1 (GLP-1). ${ }^{16-21}$ After being secreted by intestinal L-cells and pancreatic $\alpha$-cells, ${ }^{22,23}$ GLP-1 enhances insulin secretion by $\beta$-cells in response to carbohydrate ingestion. ${ }^{24}$ GLP-1 has hormonal feedback pathways as well as neural pathways ${ }^{24}$ and has also been shown to reduce feelings of hunger and increase satiety. ${ }^{25}$ Other pathways of action of GLP-1 include upregulation of insulin biosynthesis and decreased secretion of glucagon by the liver. ${ }^{26}$ Grape compounds are known to modulate incretin levels. ${ }^{16,27}$ Orally administered procyanidins increase blood GLP-1 and insulin levels. ${ }^{17}$ Grape flavan-3-ols also inhibit dipeptidyl-peptidase IV, the enzyme that cleaves GLP-1 and thus reduces its half-life and activity. ${ }^{18}$

The overall impacts of grapes and grape constituents on glucose control have been studied, but the mechanisms have not been rigorously isolated and tested in vivo. Increased GLP-1 and insulin secretion are well known to be associated with administration of grape flavan-3-ols, but it remains unknown whether grapes directly improve glucose clearance via GLP-1 signalling. It also remains to be established whether grape constituents act primarily in the gut (where GLP-1 is secreted) or in peripheral tissues such as skeletal muscle, liver and adipose tissue. The hypothesis that ingested grape flavan3-ols may exert their anti-diabetic effects by acting locally in the gut is supported by the fact that flavan-3-ols (particularly procyanidins) are poorly absorbed from the gut. ${ }^{28}$ Furthermore, procyanidins have been shown to improve glucose tolerance when glucose is administered orally but not when glucose is administered by intraperitoneal (i.p.) injection. ${ }^{18}$ Therefore, the mechanism by which grapes and their constituents may improve glucose tolerance may involve increasing circulating GLP-1 levels, thereby improving the insulin response to a meal and/or increasing satiety. This mechanism is currently exploited by a class of pharmaceuticals known as gliptins (sitagliptin, vildagliptin, saxagliptin, etc.) which are employed as $2^{\text {nd }} / 3^{\text {rd }}$ line treatment agents in T2DM poorly controlled by metformin alone. ${ }^{29}$ However, it remains to be demonstrated whether dietary strategies such as grape consumption can effectively target this mechanism to improve glucose homeostasis and control prediabetes in normoglycemic and prediabetic models.

The objectives for this study were to (1) determine whether acute grape consumption impacts glucose control via the GLP-1 signaling pathway, and (2) determine if acute and longterm grape consumption improves glycemic control in normoglycemic and prediabetic (via diet-induced obesity) mouse models. Additionally, this study employed a well-defined ${ }^{30-35}$ freeze-dried grape powder made from whole grapes in order to determine if beneficial effects from grape constituents could be achieved after consumption of whole grapes.

\section{Materials and methods}

\subsection{Grape powder composition and analysis}

Homogenized, freeze-dried grape powder (FDGP, provided by the California Table Grape Commission, Fresno, CA via The National Food Lab, Livermore, CA) made from whole, ripe, seeded, and seedless red, green, and black California table grapes was used for all studies. The grape varieties used in this powder are matched to consumer consumption patterns, and $23 \mathrm{~g}$ of powder is equivalent to 1 serving of fresh grapes (3/4 cup or $126 \mathrm{~g}$ ). FDGP is used in place of fresh, whole grapes in order for ease of administering treatments and experimental reproducibility. FGDP is made by freezing and grinding with food-grade dry ice, freeze-drying, and re-grinding; Good Manufacturing Practices for food products were employed throughout processing. FDGP was maintained at $-80{ }^{\circ} \mathrm{C}$ when not in use. Per the California Table Grape Commission, FDGP contains $\sim 90 \%$ sugar (w/w) (1:1 fructose : glucose).

Grape powder was subjected to several analyses including characterization of the polyphenol profile and proximate analysis. The 4-dimethylaminocinnamaldehyde (DMAC) colorimetric method was used to quantify total flavan-3-ol content, using a method adapted from analysis of procyanidins in cranberry powder. ${ }^{36}$ Total phenolics were assessed (whole FDGP and polyphenol extract were both assessed) using the FolinCiocalteu reagent. ${ }^{37}$ Anthocyanin content of the grape powder 
was assessed via a slightly modified spectrophotometry method. ${ }^{38}$ A sample size of $n=4$ was employed for all assays.

A modified extraction was performed per California Table Grape Commission guidelines ${ }^{39}$ to isolate polyphenolic compounds for analysis. FDGP (100.27 g) was dissolved in $600 \mathrm{~mL}$ Milli-Q water and stirred for $1.5 \mathrm{~h}$ with a magnetic stir plate at $400 \mathrm{RPM}$. This suspension was centrifuged for $20 \mathrm{~min}$ $\left(612 g\right.$ at $\left.10^{\circ} \mathrm{C}\right)$ and the supernatant was collected and refrigerated. $300 \mathrm{~mL}$ methanol (Sigma-Aldrich, St. Louis, MO) was added to the pellet to further extract any polyphenols; the suspension was stirred, centrifuged and the supernatant collected (under the same conditions as above). The pellet was submitted to a final extraction with $300 \mathrm{~mL}$ of $70 \%$ acetone, $28 \%$ water, $2 \%$ glacial acetic acid (v/v/v); this suspension was agitated with a polytron (Brinkmann Instruments, Rexdale, Canada) for $1 \mathrm{~min}$, sonicated for $30 \mathrm{~s}$ at $40 \%$ with a tip ultrasonicator (Fisher Scientific, Pittsburgh, PA). This solution was centrifuged and the supernatant was pooled with the previous supernatants. Volatile solvents were removed from pooled supernatants by rotary vacuum evaporation in a Rotovap (IKA RV10 Basic, Staufen, Germany, $45^{\circ} \mathrm{C}$ ), and the dried sample was refrigerated.

An open chromatography column $(5 \mathrm{~cm} \times 60 \mathrm{~cm})$ was prepared with $500 \mathrm{~g}$ Diaion HP-20 (Sigma-Aldrich, St. Louis, MO) stationary phase per manufacturer instructions, and equilibrated with $\sim 8$ L distilled water ( $10 \times$ column bed volume).

The FDGP extract was slowly loaded onto the column over a period of $20 \mathrm{~min}$. The column was first eluted with water $(\sim 3 \mathrm{~L}$ water); this cloudy eluent containing sugars and other polar compounds was discarded. Next, the column was eluted with $\sim 2 \mathrm{~L}$ methanol followed by $\sim 500 \mathrm{~mL}$ acetone to completely elute all desired polyphenolic compounds off the column; all eluents were collected and pooled (see Fig. S1 $\dagger$ ). The pooled eluents were dried by rotary evaporation as described above in order to remove volatile solvents from the solution. The remaining aqueous solution was lyophilized at $-50{ }^{\circ} \mathrm{C}$ (Labconco FreeZone 1, Kansas City, MO). The final dry extract yield of the FDGP $(0.8787 \mathrm{~g}, 0.876 \%$ yield $)$ was stored at $-80{ }^{\circ} \mathrm{C}$.

Standard methods were employed for proximate analysis of FDGP. Moisture content was determined via drying in a vacuum oven at $70{ }^{\circ} \mathrm{C}$ for $3 \mathrm{~h}$ under a vacuum of 23 in $\mathrm{Hg}$ (gauge pressure); moisture was calculated by weight difference. Ash content was measured via dry ashing (ashed at $600{ }^{\circ} \mathrm{C}$ for $24 \mathrm{~h}$ ), and calculated by weight difference. Lipid content was determined by Soxhlet. Crude protein content was determined by Kjeldahl (Nx6.25). A sample size of $n=4$ was used for proximate analysis. Carbohydrate content (on a wet weight basis, wwb) was determined by difference:

$$
\begin{aligned}
& \% \text { carbohydrate }(\mathrm{wwb})=100 \% \\
& \quad-[\% \text { moisture }+\% \text { ash }+\% \text { lipid }+\% \text { protein }](\mathrm{wwb})
\end{aligned}
$$

\subsection{Experimental diets and treatments}

As FDGP is $\sim 90 \%$ sugars (by weight) of a $1: 1$ mixture of glucose and fructose, these sugars (Sigma Aldrich, St. Louis, MO) were used as a control ("sugar-matched control") for acute and chronic experiments. Basal high-fat (HF, D12492) and standard (S, D12450J) diets containing 60\% and $10 \% \mathrm{kcal}$ from fat, respectively, and matched for sucrose content were obtained from Research Diets (New Brunswick, NJ). Specialized diets were produced from these basal diets by Research Diets, which incorporated the FDGP at $5 \% \mathrm{w} / \mathrm{w}$ and the sugar mixture at $4.5 \% \mathrm{w} / \mathrm{w}$ (i.e. $2.25 \%$ fructose $\mathrm{w} / \mathrm{w}$ and $2.25 \%$ glucose $\mathrm{w} / \mathrm{w}$, a total of $4.5 \%=$ equivalent to $90 \%$ of $5 \%$ i.e. the sugar added by FDGP) (Table 2). Detailed information about the composition of these diets can be found in ESI, Table S1. $\dagger$ All diets were maintained at $4{ }^{\circ} \mathrm{C}$ throughout the study in order to prevent rancidity.

\subsection{Impact of oral grape powder administration on GLP-1 receptor antagonism (Study 1)}

All animal experiments were performed in accordance with American Veterinary Medical Association (AVMA) Guidelines

Table 1 Composition of freeze dried grape powder

\begin{tabular}{ll}
\hline Component & Amount per $100 \mathrm{~g}( \pm \mathrm{SEM})$ \\
\hline Protein $(\mathrm{g})$ & $3.39 \pm 0.74$ \\
Carbohydrates $(\mathrm{g})$ & 92.36 \\
Fat $(\mathrm{g})$ & $0.14 \pm 0.03$ \\
Moisture $(\mathrm{g})$ & $1.46 \pm 0.066$ \\
Ash $(\mathrm{g})$ & $2.65 \pm 0.036$ \\
Total polyphenols & $(\mathrm{mg})$ \\
Total flavanols $^{b}\left(\mathrm{mg}^{c}\right)$ & $323.6 \pm 8.09$ \\
Total anthocyanins $^{c}(\mathrm{mg})$ & $59.44 \pm 0.86$ \\
& $9.62 \pm 0.14$
\end{tabular}

${ }^{a}$ Gallic acid equivalents, as measured by Folin-Ciocalteu. ${ }^{b}$ Procyanidin B2 equivalents, as measured by DMAC. ${ }^{c}$ Cyandin-3-glucoside equivalents, as measured by the $\mathrm{pH}$-shift assay.

\begin{tabular}{|c|c|c|c|c|}
\hline $\begin{array}{l}\text { Supplier } \\
\text { diet } \text { ID }^{a}\end{array}$ & D12450J & D12492 & D14090308 & D14090309 \\
\hline Identification & Standard fat & High fat & High fat with grape powder & High fat with sugar-matched control \\
\hline Abbreviation & $\mathrm{SF}$ & $\mathrm{HF}$ & $\mathrm{HF} / \mathrm{GP}$ & $\mathrm{HF} / \mathrm{SM}$ \\
\hline$\%$ kcal from fat & 10 & 60 & 60 & 60 \\
\hline$\%$ Grape powder (w/w) & 0 & 0 & 5 & 0 \\
\hline$\%$ Polyphenols $(\mathrm{w} / \mathrm{w})^{b}$ & 0 & 0 & 0.04 & 0 \\
\hline$\%$ Added sugar $(\mathrm{w} / \mathrm{w})^{c}$ & 0 & 0 & 0 & 4.5 \\
\hline
\end{tabular}

Table 2 Identification of diets used in experiments; see ESI for detailed descriptions of diet composition

${ }^{a}$ Research diets, New Brunswick, NJ. ${ }^{b}$ As determined by Folin-Ciocalteu (Table 1$) .{ }^{c} 1: 1$ (w/w) mixture of glucose : fructose. 
approved by the Institutional Animal Care and Use Committee at Virginia Tech (protocol FST 14-146). Schematics of all animal study designs (Studies 1-4) can be found in ESI (Fig. S2†). Male normoglycemic C57BL/6J mice $(N=32,11$ weeks, Jackson Labs, Bar Harbor, ME) were obtained and acclimatized for 2 weeks to vivarium conditions $(2$ mice per cage, $12 \mathrm{~h}$ light/dark period, $30-70 \%$ relative humidity, 20-26 ${ }^{\circ} \mathrm{C}$ ). Mice were allowed access to standard diet (D12450J diet, Research Diets, New Brunswich, NJ) and water ad libitum during acclimatization. Mice were randomized by weight (mice were ranked in order of ascending weight, then assigned to treatment group) to equalize any differential effects of bodyweight. Mice were assigned to treatment groups with a $2 \times 2$ design: GLP-1 receptor antagonist exendin-3 (9-39) amide (Santa Cruz Biotechnology, Dallas, TX) vs. vehicle (saline) ( $n=15 / 16$ per group); these treatment groups were further split into FDGP $(n=8)$ or sugar-matched control $(n=7 / 8)$ groups. All treatment groups were subjected to a concurrent oral glucose tolerance test (OGTT) by adding $0.5 \mathrm{~g}$ glucose per $\mathrm{kg}$ bodyweight to the treatment solution. This glucose load ( $0.5 \mathrm{~g}$ glucose per $\mathrm{kg}$ bodyweight) was chosen instead of a standard 1 or $2 \mathrm{~g}$ glucose per $\mathrm{kg}$ bodyweight because the grape/ sugar-matched control administration adds an additional glucose load of $0.72 \mathrm{~g}$ glucose per $\mathrm{kg}$ bodyweight and an additional fructose load of $0.72 \mathrm{~g}$ glucose per $\mathrm{kg}$ bodyweight. Mice were fasted for $12 \mathrm{~h}$ followed by intraperitoneal (i.p.) injection: exendin-3 (9-39) amide ( $25 \mathrm{nmol}$ per $\mathrm{kg}$ bodyweight) in saline, or saline vehicle (equal volume). Immediately following injection, mice were administered by intragastric gavage: suspension of FDGP (1.6 g per kg body weight) plus glucose ( $0.5 \mathrm{~g}$ per $\mathrm{kg}$ bodyweight) in saline, or sugar matched control (1.44 $\mathrm{g}$ per $\mathrm{kg}$ bodyweight) plus glucose (0.5 g per kg bodyweight) in saline. Blood glucose levels were then quantified at baseline and 10, 30, 60, 90, and 120 min post-gavage via blood expressed from the tail tip using a glucometer (OnePlus Touch UltraMini, Milpitas, CA) and OneTouch Ultra Blue glucose test strips. Blood $(\sim 50-100 \mu \mathrm{L})$ was also collected via the tail at 10 and $30 \mathrm{~min}$ in $400 \mu \mathrm{L}$ micro serum separation tubes (Fisher Scientific, Pittsburgh, PA), clotted at room temperature for $2 \mathrm{~h}$, and centrifuged at $17000 \mathrm{~g}$ for $10 \mathrm{~min}$ at room temperature. Separated serum was pipetted from these tubes into microfuge tubes containing $5 \mu \mathrm{L} 100 \times$ Thermo HALT protease inhibitor (Fisher Scientific, Waltham, MA). Serum samples were stored at $-80{ }^{\circ} \mathrm{C}$.

\subsection{Impact of oral $v s$. i.p. grape powder administration on glycemic response (Study 2)}

Mice $(N=29)$ from Study 1 were given a 2 -week rest/recovery period before the initiation of Study 2, during which the standard diet and water were provided ad libitum. Mice were fasted for $12 \mathrm{~h}$ prior to treatment, and re-randomized into a $2 \times 2$ design: grape powder aqueous suspension (1.6 $\mathrm{g}$ per $\mathrm{kg}$ bodyweight) $(n=15)$ vs. sugar-matched aqueous suspension control group (1.44 g per kg bodyweight) $(n=14)$; these treatment groups were divided in half into i.p. administration $(n=7) v s$. oral administration $(n=7 / 8)$. The mice were given this treat- ment followed by OGTT ( $0.5 \mathrm{~g}$ glucose per $\mathrm{kg}$ bodyweight); for the oral grape and oral sugar-matched treatments, the OGTT was administered in the same gavage as the treatment solution. Blood glucose levels were quantified as in Study 1 with an additional time point at $180 \mathrm{~min}$ to ensure the entire glycemic response was captured. Blood collections were taken at 10 and $30 \mathrm{~min}$ and serum obtained as described above. Following this study, mice were euthanized by $\mathrm{CO}_{2}$ followed by bilateral pneumothorax, according to American Veterinary Medical Association (AVMA) guidelines.

\subsection{Impact of oral grape powder administration on glycemic response in normoglycemic and prediabetic mice (Study 3)}

Prediabetic (PD) male C57BL/6J mice $(N=16,11$ weeks old, with diet-induced obesity, Jackson Labs, Bar Harbor, ME) and normoglycemic (NG) male C57BL/6J mice $(N=32,11$ weeks old, Jackson Lab, Bar Harbor, ME) were obtained and acclimated to vivarium conditions for 2 weeks as described above. PD mice were maintained on the HF basal diet (D12492); NG mice were maintained on the standard basal diet (D12450J). Mice were given food and water ad libitum.

Mice from each phenotype $(N=16$ per phenotype, note that $n=16$ of the NG mice were not used for this part of the study) were then randomized by weight as above. Mice from each phenotype were separated into two treatment groups: grape powder or sugar-matched control ( $n=8$ per phenotype/treatment group). Mice were fasted for $12 \mathrm{~h}$, after which the treatments were delivered via intragastric gavage: grape (1.6 g grape powder per $\mathrm{kg}$ bodyweight) plus glucose $(0.5 \mathrm{~g}$ per $\mathrm{kg}$ bodyweight) suspended in saline or sugar-matched control $(1.44 \mathrm{~g}$ sugar mixture per $\mathrm{kg}$ mouse) plus glucose ( $0.5 \mathrm{~g}$ per $\mathrm{kg}$ bodyweight) suspended in saline. Blood glucose levels were quantified as in Study 2; and blood collections were taken at 10 and $30 \mathrm{~min}$ followed by serum separation as above.

\subsection{Impact of long-term grape powder consumption on glycemic control in prediabetic and normoglycemic mice (Study 4)}

Mice from Study 3 were given a 2-week rest/recovery period under the vivarium and diet conditions described above (PD mice fed HF diet and NG mice fed SF diet). The $n=16 \mathrm{NG}$ mice that had not been used in Study 3 were maintained on the standard basal diet during this time. At the beginning of the long-term feeding study, mice were randomized to treatment diets as seen in Table 3. PD mice were switched to highfat diets + grape treatment (HF/GR) or high fat diets + sugar-

Table 3 Treatment groups for Study 4

\begin{tabular}{lllllll}
\hline Mouse phenotype $^{a}$ & NG & NG & NG & NG & PD & PD \\
\hline Treatment diet $^{b}$ & SF & HF & HF/SM & HF/GR & HF/SM & HF/GR \\
$N$ & 8 & 8 & 8 & 8 & 8 & 8
\end{tabular}

${ }^{a} \mathrm{NG}$ - normoglycemic; PD - prediabetic. ${ }^{b} \mathrm{SF}$ - standard fat diet; HF high fat diet; HF/SM - high fat diet sugar matched to grape powder; HF/GR - high fat diet with grape powder. 
matched control (HF/SM) (5\% and $4.5 \% \mathrm{w} / \mathrm{w}$, respectively). NG mice were switched to the following diets: HF, HF/SM, HF/GR, and SF. For all groups, $n=8$ was employed at the start of the study.

Feed was replaced twice per week, as oxidative rancidity of lipids in HF diets may alter consumption patterns (due to sensory characteristics) and/or introduce toxic lipid oxidation products into the diet; food consumption was measured by weighing food placed in the cage and food taken from the cage during the feed changes. Mouse bodyweight was recorded weekly. Body composition scans were completed during weeks 4 and 8 (Bruker LR90 NMR minispec, Billerica, MA). During week 9, an i.p. glucose tolerance test (GTT) was performed. Mice were fasted for $12 \mathrm{~h}$, followed by i.p. injection of a $20 \%$ $(\mathrm{w} / \mathrm{v})$ glucose solution (Sigma Aldrich, St. Louis, MO) in saline to provide $1 \mathrm{~g}$ glucose per $\mathrm{kg}$ bodyweight. Baseline, 30, 60, 90 and $120 \mathrm{~min}$ blood glucose levels were measured as described above. Following a 1-week recovery period (water and treatment diets ad libitum), an i.p. insulin tolerance test (ITT) was performed. Mice were fasted for $4 \mathrm{~h}$ followed by i.p. injection of insulin (Humulin R, Cardinal Health, Dublin $\mathrm{OH}$ ) in saline to provide $0.65 \mathrm{U}$ per $\mathrm{kg}$ bodyweight. Baseline, 15, 30, 45 and $60 \mathrm{~min}$ blood glucose levels were quantified as described above; any mice approaching hypoglycemia were administered an i.p. injection of $20 \%$ glucose (w/v) and no further data points were collected in these mice.

Following the above treatments, all mice from the study were euthanized as described above immediately followed by a blood collection via cardiac puncture. Serum was prepared as described above $(10 \mu \mathrm{L} 100 \times$ HALT protease inhibitor was added to serum separation tubes) and stored at $-80{ }^{\circ} \mathrm{C}$. Small intestine, colon and liver samples were excised from the mice, rinsed with cold $1 \times$ phosphate-buffered saline (intestinal tissues only, VWR, Radnor, PA), placed in Trizol reagent (Qiagen, Valencia, CA), snap frozen in liquid nitrogen, and stored at $-80^{\circ} \mathrm{C}$.

\subsection{ELISAs}

ELISA assay kits were used to quantify GLP-1 (Multi Species GLP-1 Total ELISA, EZGLP1T-36K, Millipore, Billerica, MA) and GIP [murine GIP (total) ELISA, EZRMGIP-55K, Millipore, Billerica, MA] in duplicate (where possible) according to manufacturer instructions.

\subsection{Statistical analyses}

All blood glucose data were plotted and areas under the curve (AUC) were calculated. Blood glucose excursion was calculated by subtracting the baseline value from the maximum value achieved. Glucose and ELISA data were analyzed for significance of main effects and interactions using two-way (Studies 1-3) or one-way (Study 4) ANOVA; group means were analyzed with Tukey's HSD. Significance was defined as $p<0.05$. All statistical analyses were performed on GraphPad Prism software (v6, La Jolla, CA).

\section{Results}

\subsection{Composition of grape powder}

The composition of the grape powder (flavanol, anthocyanin and polyphenol contents; proximate composition) is shown in Table 1. The grape powder contained $93.4 \%$ carbohydrates by weight, which roughly agrees with the sugar content specified by the California Table Grape Commission ( $90 \%$ sugar). The total polyphenol content was calculated as $0.324 \%$ by the Folin-Ciocalteu assay (324 mg gallic acid equivalents per $100 \mathrm{~g}$ grape powder); while previously published data indicated $580 \mathrm{mg}$ total phenols per $100 \mathrm{~g}^{\mathrm{FDGP}}{ }^{33}$ The content of total flavanols, as measured by DMAC, was $0.0594 \%$ (59.44 mg procyanidin B2 equivalents per $100 \mathrm{~g}$ grape powder), while previous data indicated $410 \mathrm{mg}$ flavanols per $100 \mathrm{~g}$ grape powder. ${ }^{33}$ Based on our data, the acute dose of $1.6 \mathrm{~g}$ per $\mathrm{kg}$ is equivalent to $0.950 \mathrm{mg}$ per $\mathrm{kg}$ total flavanols; the chronic dose of $5 \%(\mathrm{w} / \mathrm{w})$ in the diet corresponds to $0.00297 \%$ total flavanols in the diet. For the long term study, this means that the normoglycemic grape treatment group received $2.67 \mathrm{mg}$ total flavanols per $\mathrm{kg}$ per $\mathrm{d}$ based on daily feed consumption $(\sim 90 \mathrm{~g}$ $\left.\mathrm{kg}^{-1} \mathrm{~d}^{-1}\right)$, and the prediabetic treatment group received $2.08 \mathrm{mg}$ total flavanols per $\mathrm{kg}$ per $\mathrm{d}$ based on daily feed consumption $\left(\sim 70 \mathrm{~g} \mathrm{~kg}^{-1} \mathrm{~d}^{-1}\right)$.

\subsection{Impact of oral grape administration on GLP-1 receptor antagonism (Study 1)}

The goal of Study 1 was to determine the role played by GLP-1 in the glycemic response to oral glucose during grape consumption. A GLP-1 antagonist, exendin-3 (9-39) amide, was used in this study to inhibit the action of GLP-1. Exendin3 has been shown to be an antagonist of GLP-1 receptors that has the capability of displacing GLP-1 at $70 \% .{ }^{40}$ Mice were given an i.p. injection of exendin-3 (9-39) followed by intragastric gavage of grape powder suspension to observe the effect of GLP-1 receptor antagonism on OGTT administered with grape solution.

Blood glucose profiles. Blood glucose profiles for Study 1 are shown in Fig. 2A-E. In this experiment, blood glucose was monitored over $120 \mathrm{~min}$; however, it was determined that more time was needed in order for blood glucose levels to return to baseline (this obscures a complete picture of the data). This was likely due to oral administration of glucose (as opposed to i.p. or i.v. delivery, which facilitates faster glucose appearance in and clearance from the bloodstream). This was addressed for subsequent studies: blood glucose levels were monitored for 180 minutes. Fig. 2A shows the glycemic responses of all four treatments on the same graph; for ease of comparison, Fig. 2B-E compare blood glucose profiles from different pairs of the treatments. Blood glucose profiles from the sugar match treatment (+saline or +GLP-1 antagonist) are shown in Fig. 2B. Administration of exendin-3 (9-39) clearly inhibited blood glucose clearance within the sugar-matched control group, as identical peak levels were reached (10 min), but the levels in the +GLP-1 antagonist group were higher from 60-120 min. Interestingly, this effect seen in the sugar- 

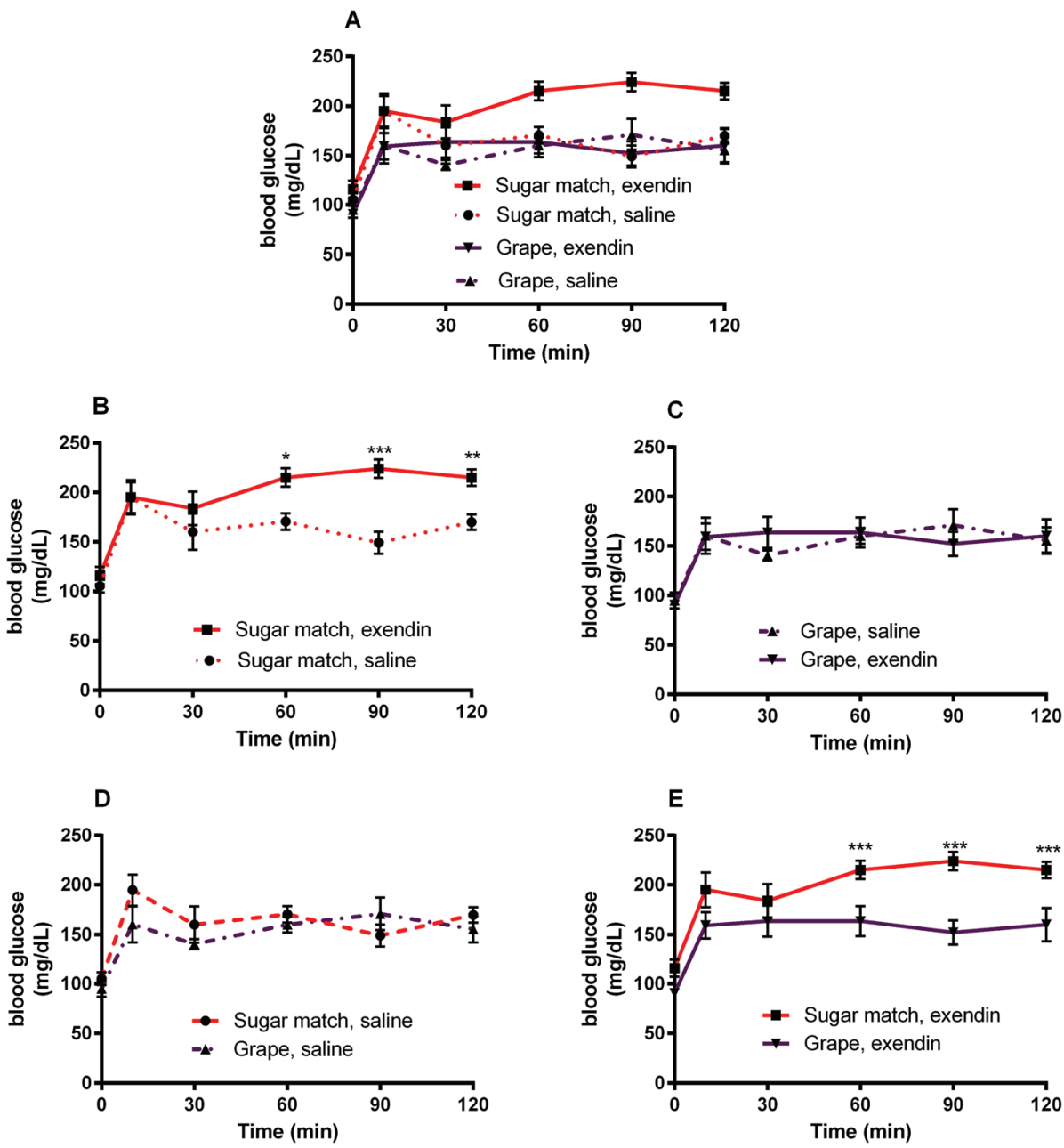

Fig. 2 Blood glucose response curves after intraperitoneal administration of GLP-1 receptor antagonist [exendin-3 (9-39) amide] (or vehicle, saline) followed by intragastric gavage of grape powder or sugar-matched control. (A) All treatments, (B) sugar match: exendin-3 vs. vehicle, (C) grape powder: exendin-3 vs. vehicle, (D) vehicle: grape powder vs. sugar match, (E) exendin-3, grape powder vs. sugar match. Values are mean \pm SEM $(n=$ 8). ${ }^{*} p<0.05{ }^{* *} p<0.01 * * * p<0.001$ indicate significant difference between two treatment means at the specified time point as indicated by twoway ANOVA with Tukey's HSD post hoc test (significance is indicated only on graphs with paired curves for ease of interpretation).

matched control was not seen when grape powder was administered (Fig. 2C). Oral administration of grape powder reversed the deleterious effect of GLP-1 antagonism by exendin-3 (9-39) compared to oral administration of the sugarmatched control (Fig. 2E). However, despite the reversal of GLP-1 antagonism by grape powder, grape did not significantly lower blood glucose levels versus sugar match when both were co-administered with saline control (Fig. 2D).

AUC/excursion/single time point data. From the blood glucose profiles, the AUC for each curve was calculated (Fig. 3A). This measure represents the total glycemic response as it accounts for the peak concentration in blood glucose as well as how quickly post-treatment blood glucose levels dropped. AUC values in Fig. 3A generally reflected the patterns of the blood glucose curves seen in Fig. 2. Within the sugarmatched treatment, GLP-1 receptor antagonism significantly raised the glucose AUC vs. saline control $(p<0.01)$. The impact of GLP-1 receptor antagonism was alleviated by the grape treatment compared to sugar match $(p<0.01)$. Interestingly, within the grape treatment, the AUC was not elevated by exendin-3 (9-39) compared to saline control; grape appeared to block, or alleviate, GLP-1 receptor antagonism by exendin-3 (9-39) but did not improve glycemic response when GLP-1 signalling was not disturbed. In addition to AUC values, blood glucose levels at specific time points, excursions from baseline, and changes between specific time points were determined (Fig. 3BG). Grape treatments caused a significant reduction in blood glucose levels at 10 minute versus sugar-matched control, regardless of whether exendin-3 (9-39) or saline was administered (Fig. 3E). No significant interactions were observed in the other time points, although GLP-1 receptor antagonism exerted a borderline significant $(p=0.079)$ effect on the change in blood glucose between 10-30 min, regardless of whether sugar match or grape treatment was administered (Fig. 3G). 

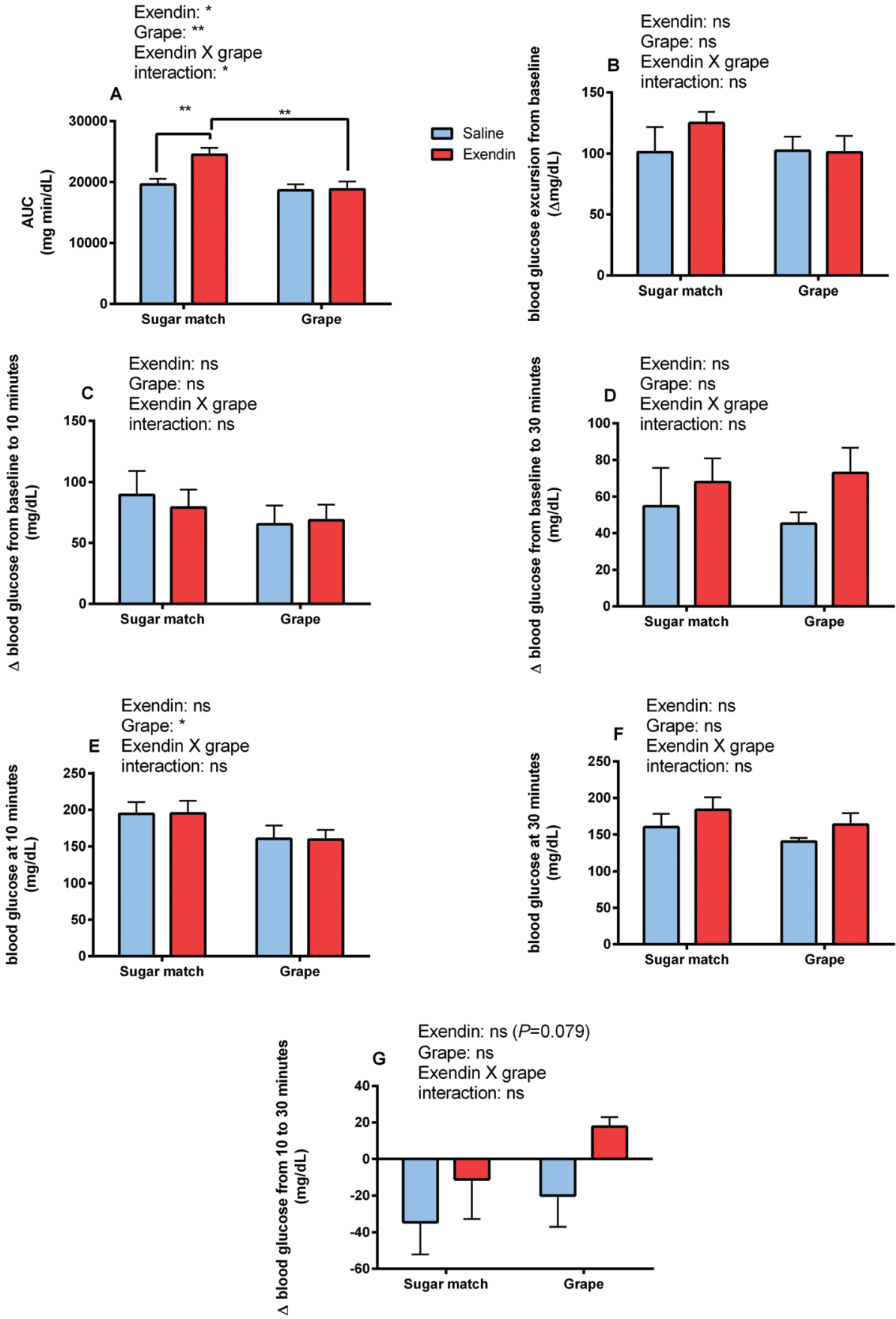

Fig. 3 Glycemic responses parameters after intraperitoneal administration of GLP-1 receptor antagonist [exendin-3 (9-39) amide] or vehicle followed by intragastric gavage of grape powder or sugar-matched control. (A) Blood glucose area under the curve (AUC), (B) blood glucose excursion (maximum value minus baseline value), (C) baseline to $10 \mathrm{~min}$ change in blood glucose, (D) baseline to 30 min change in blood glucose, (E) blood glucose level at $10 \mathrm{~min}$, (F) blood glucose level at $30 \mathrm{~min}$ (G) change in blood glucose from 10 to $30 \mathrm{~min}$. Values are mean \pm SEM ( $n=8$ ). Legends above individual graphs indicate treatment main effects as determined by two-way ANOVA. ${ }^{*} p<0.05{ }^{* *} p<0.01{ }^{* * *} p<0.001$ indicate significant difference between treatment means as indicated by two-way ANOVA with Tukey's HSD post hoc test.

Serum GLP-1 quantification. Total GLP-1 levels were quantified at 10 and 30 min after treatments in Study 1 (Fig. 4A and B). There were no significant differences observed between any of the treatments; at the 30 min time point the exendin-3 (9-39) with grape treatment had lower serum GLP-1 than the saline vehicle with grape treatment.

\subsection{Impact of oral vs. i.p. grape administration on glycemic} response (Study 2)

The purpose of Study 2 was to determine the relative effects of grape powder on glycemic control via mechanisms located in the gut vs. mechanisms located in circulation. The grape 

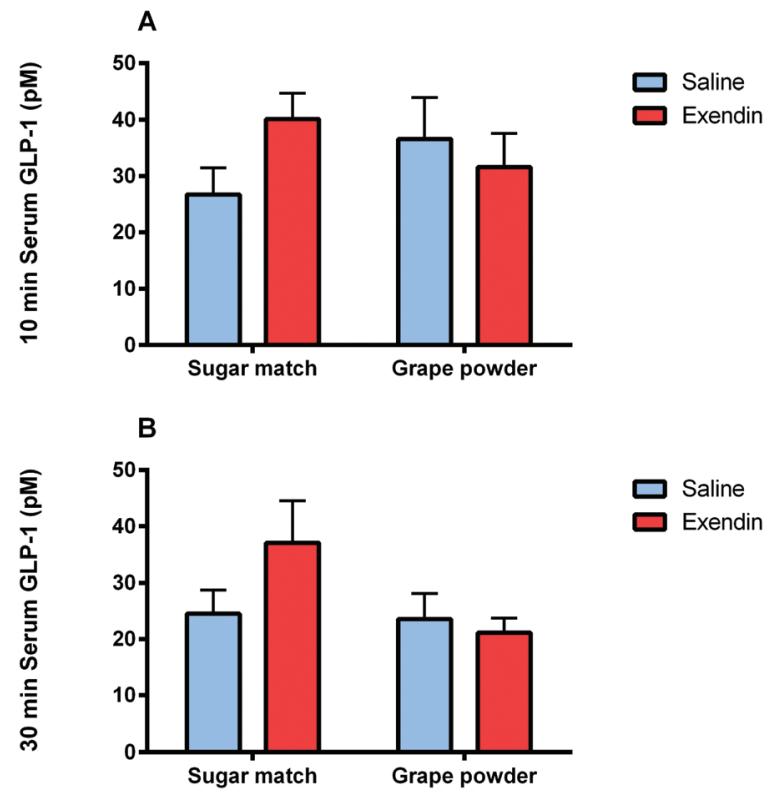

Fig. 4 Serum insulin and GLP-1 levels as quantified by ELISA assays. (A) serum GLP-1 levels at 10 min in Study 1 after exendin-3 (9-39) antagonism of GLP-1 receptors and subsequent grape powder vs. sugarmatched control administration, (B) serum GLP-1 levels at $30 \mathrm{~min}$ in Study 1 after exendin-3 (9-39) antagonism of GLP-1 receptors and subsequent grape powder vs. sugar-matched control administration. Values are mean $\pm \mathrm{SEM}$; for significance was tested with two-way ANOVA with Tukey's HSD post hoc test.

powder suspension was administered via differing routes (i.p. injection versus intragastric gavage) followed by an oral glucose tolerance test. Blood glucose levels were monitored for $3 \mathrm{~h}$ after the treatment to determine the effects of grape powder administration in the gut versus in peripheral tissue. The grape powder solution was insoluble in the i.p. injection vehicle and thus delivered insoluble components to the i.p. cavity. This is therefore not representative of physiological delivery to the i.p. cavity and bloodstream, where only soluble compounds would be delivered; the results of this part of the study are therefore included in the ESI. $\dagger$ For results of all treatments, see Fig. S3 and S4. $\dagger$ Data for serum GLP-1 and serum insulin levels can be found in the ESI. $\dagger$

\subsection{Impact of acute and long term oral grape administration} on glycemic response in normoglycemic and prediabetic mice (Studies 3 and 4)

The goal of Study 3 was to observe and analyze how consumption of grape powder affects post-prandial circulating blood glucose levels in the context of normoglycemia as well as prediabetes/hyperglycemia. No significant differences in blood glucose AUC were found between grape powder and sugarmatched treatments in either normoglycemic or prediabetic mice after oral glucose tolerance test. See Fig. 5 for OGTT data including blood glucose AUCs and glucose time series among the different treatments and phenotypes.

Study 4 was the long-term feeding study featuring an 8 -week feeding period with grape powder $(5 \% \mathrm{w} / \mathrm{w}$ of mouse feed) or control (glucose/fructose at $4.5 \% \mathrm{w} / \mathrm{w}$ of mouse feed) incorporated into high fat diets (60\% kcal from fat) in both prediabetic and normoglycemic models. After 8 weeks of feeding, insulin tolerance (ITT) and glucose tolerance (GTT) tests were performed to determine how chronic grape feeding affects glycemic response and insulin sensitivity. This study was designed to show the efficacy of grape powder to ameliorate prediabetes in mice with the preexisting condition; additionally this work was designed to show if the grape powder can prevent the onset of prediabetes in normoglycemic mice after switching to a high fat diet. However, no significant differences were seen in ITT, GTT or body weight due to grape powder. Bodyweight, feed intake, and weight gain data can be found in Table S2. $\uparrow$ A blood collection was performed in all mice immediately post-sacrifice after a $12 \mathrm{~h}$ fast and fasting GLP-1 and GIP levels were quantified (see ESI $\dagger$ for results figures and further discussion of Studies 3 and 4).

\section{Discussion}

The present study was designed to explore the mechanisms of enhanced glycemic control by grape powder constituents. To the best of our knowledge, this is the first study to build upon the known GLP-1 promoting activities of grape extracts and demonstrate that whole grapes beneficially modulates GLP-1 levels or function. ${ }^{16,18,19,27}$ Initially, we hypothesized that acute administration of grape powder would significantly reduce glycemic response compared to sugar-matched control; however, grape powder and sugar-matched control displayed similar blood glucose AUCs after OGTT (Study 3). However, Study 1 was designed to observe the impact of grape consumption on glycemic response when the GLP-1 signalling pathway is blocked; interestingly, grape consumption actually reversed the deleterious glycemic effects of GLP-1 receptor antagonism (Fig. 2 and 3). This has interesting potential implications, as consumption of grapes may be capable of improving impaired GLP-1 signalling and, by extension, restoring glycemic control induced by impaired GLP-1 signalling.

Exendin-3 (9-39) is a potent antagonist at the GLP-1 receptor. ${ }^{40}$ Exendin-3 (9-39) was used in Study 1 to inhibit GLP-1 signalling in order to cause a dysregulation of post-prandial incretin action and subsequent insulin secretion; insulin secretion by pancreatic $\beta$-cells in response to glucose consumption is partially dependent on activation by incretin activity of GLP-1 and GIP. ${ }^{41}$ In the sugar-matched treatment group, GLP-1 receptor antagonism by exendin-3 (9-39) caused a significant $(p<0.01)$ increase in blood glucose AUC after OGTT compared with the saline vehicle control (Fig. 2). However, when grape powder was co-administered with OGTT following GLP-1 receptor antagonism by exendin-3 (9-39), blood glucose concentrations and AUC were significantly reduced compared to the sugar-matched control also antagonized by exendin-3 (9-39) (Fig. 2 and 3). This is a novel finding that suggests that grape consumption potentially modulates GLP-1 signalling pathways and can be exploited to improve glucose homeostasis. However, our data suggest that this 

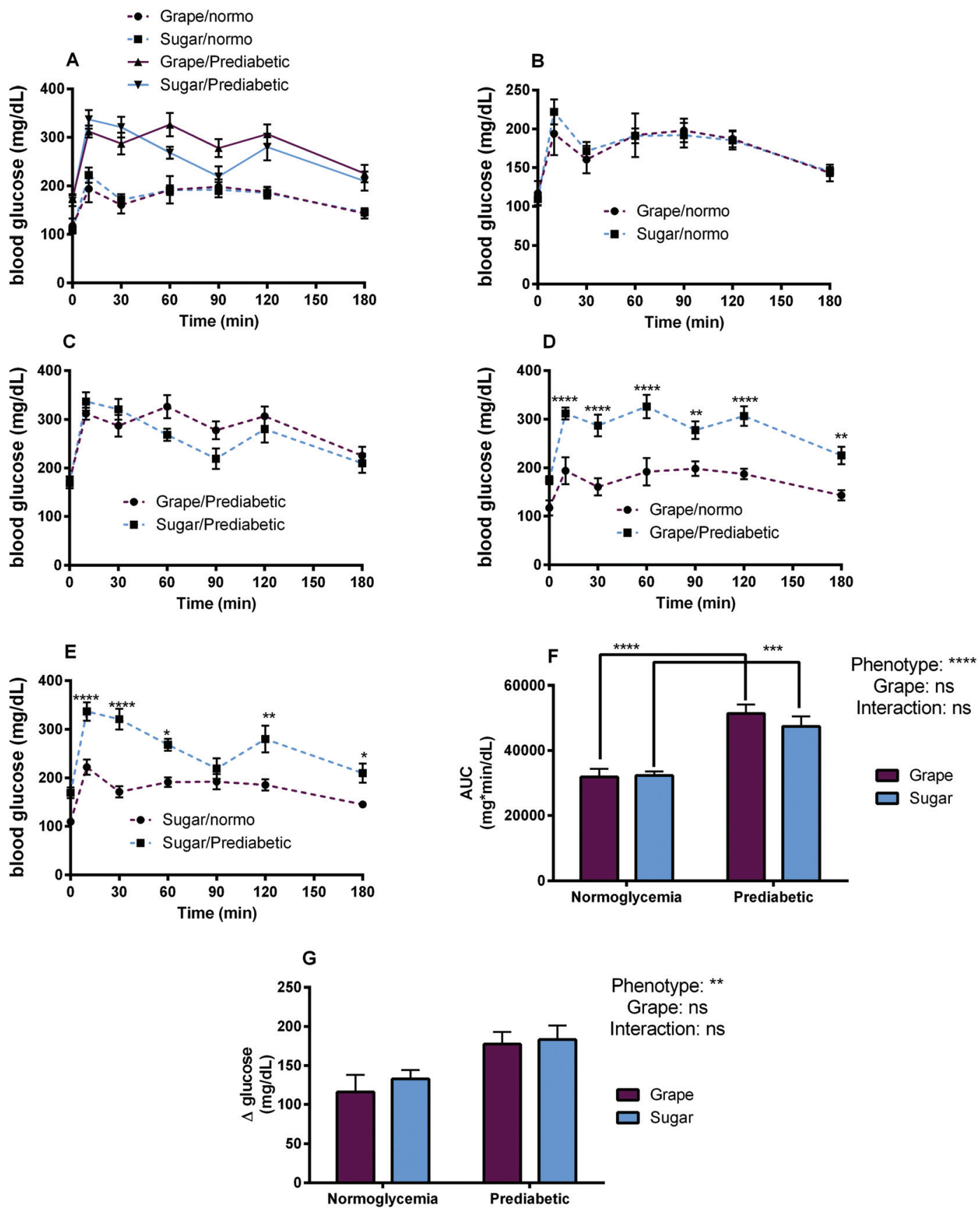

Fig. 5 Blood glucose response curves and glycemic response parameters after oral glucose tolerance test with oral administration of grape powder compared to sugar matched control via oral in prediabetic vs. normoglycemic mice. (A) Blood glucose profiles for all treatments, (B) blood glucose profiles for normoglycemic mice: grape powder vs. sugar match, (C) blood glucose profiles for prediabetic mice: grape powder vs. sugar match, (D) blood glucose profiles for grape powder: normoglycemic vs. prediabetic mice, (E) sugar-match: normoglycemic vs. prediabetic mice, (F) blood glucose area under the curve (AUC), (G) blood glucose excursion (maximum value minus baseline value). Values are mean $\pm \mathrm{SEM}(n=8)$. For $\mathrm{B}-\mathrm{E},{ }^{*} p$ $<0.05 * * p<0.01 * * * p<0.001$ indicate significant difference between two treatment means at the specified time point as indicated by two-way ANOVA with Tukey's HSD post hoc test (significance is indicated only on graphs with paired curves for ease of interpretation). For F-G, legends above individual graphs indicate treatment main effects as determined by two-way ANOVA. ${ }^{*} p<0.05{ }^{* *} p<0.01{ }^{* * *} p<0.001$ indicate significant difference between treatment means as indicated by two-way ANOVA with Tukey's HSD post hoc test.

effect may be limited to cases where defective GLP-1 signalling contributes to hyperglycemia.

The acute grape powder administration may have achieved this effect by increasing GLP-1 secretion, thereby displacing the GLP-1 receptor antagonist from the active binding sites. A previous study illustrated that grape seed procyanidin extract significantly increases active GLP-1 levels after oral glucose load. ${ }^{19}$ This increased GLP-1 secretion may have displaced the 
antagonist via increased competition between active GLP-1 and the antagonist at GLP-1 receptor binding sites in order to restore normal incretin activity. ${ }^{40,42}$

However, alternative mechanisms could also be responsible for the observed phenomenon. First, grape powder could inhibit the action of DPP4, thereby increasing circulating GLP-1 levels without altering secretion. Previous work has shown that acute administration of grape seed procyanidin extract reduces intestinal DPP4 activity and expression in healthy and diet-induced obese rats; ${ }^{18,19}$ however, a conflicting study showed an increase of intestinal DPP4 protein expression in rats treated with grape seed procyanindin extract. ${ }^{19}$ Second, grape powder could directly stimulate the GLP-1 receptor, mimicking the action of GLP-1. Finally, grape powder could act via other pathways to compensate for blunted GLP-1 signalling; for example, grape powder may have encouraged uptake of blood glucose via an unrelated pathway. In a cell study, exendin-3 (9-39) administration partially inhibited insulin secretion in both GIP receptor and GLP-1 receptor transfected cells, indicating that it may antagonize receptors in both of these incretin pathways so grape powder administration may have reversed antagonism of both of these receptors; however, conflicting data from a human clinical study show exendin-3 (9-39) did not affect GIP-dependent insulin secretion. ${ }^{42,43}$ These potential mechanisms warrant further experiments to elucidate the mechanism of action in order to facilitate exploitation of grapes for improved glucose homeostasis.

Interestingly, grape powder only protected from the deleterious effects of GLP-1 receptor antagonism; grape powder did not lower the blood glucose AUC compared to sugar-matched control when vehicle was administered instead of exendin-3 (9-39) (i.e. during normal GLP-1 signalling). This finding suggests that grape powder (at dosages used in the present study) exerts protective effects by compensating for impaired GLP-1 signalling; when GLP-1 signalling was not impaired, no protection was observed. A previous study showed that a $1 \mathrm{~g}$ per $\mathrm{kg}$ dose of grape seed procyanidin extract was able to significantly decrease glucose levels 20 minutes in rats after $2 \mathrm{~g}$ per kg glucose load; ${ }^{19}$ indicating that higher dosages of grape procyanidins display protection against hyperglycemia. The present study used grape powder $\left(1.6 \mathrm{~g} \mathrm{~kg}^{-1}\right)$ instead of extracts (grape flesh, skin or seed extract), delivering a $\sim 1000$ fold lower dosage of flavanols $\left(0.95 \mathrm{mg} \mathrm{kg}^{-1}\right)$ at which this protective effect was not seen. While the $1 \mathrm{~g}$ per $\mathrm{kg}$ grape seed procyanidin extract mentioned above reduced blood glucose levels following OGTT, this is an equivalent human dose of $81.1 \mathrm{mg}$ $\mathrm{kg}^{-1}$ (4.86 $\mathrm{g}$ for a $60 \mathrm{~kg}$ human), which is not translatable to humans through normal grape consumption. ${ }^{44}$ Therefore, the present dose $(\sim 0.077 \mathrm{mg}$ per $\mathrm{kg}$ polyphenols, or $4.62 \mathrm{mg}$ for a $60 \mathrm{~kg}$ human) is likely more representative of the effects likely to be observed in humans. The low concentration of polyphenols, relative to the sugar content of the grapes, may blunt the potential benefits of whole grape consumption for glucose control in many situations. This may explain the difference between the present research and previous studies using grape seed extracts.
Therefore, the benefits of grape consumption may be highly context-dependent (e.g. during morbid obesity when there is no measurable post-prandial GLP-1 secretion ${ }^{45}$ ). Further information regarding the exact mechanism by which grape powder exerts these effects may provide insight into potential opportunities to employ whole grapes as a strategy for improved glycemic control in humans.

Data show that control of the GLP-1 pathway may be altered in T2DM: GLP-1 secretion is significantly reduced in T2DM patients compared with healthy controls in response to mixedmeal challenge. ${ }^{46}$ Mice with a null (non-functioning) mutation in the exon region of the GLP-1 receptor gene exhibit elevated blood glucose following oral and intraperitoneal glucose tolerance test. ${ }^{47}$ Our results agree with these previous data that impaired GLP-1 signalling will negatively affect glucose homeostasis. GLP-1 is able to modulate glucose homeostasis through multiple pathways including gastric emptying, satiety, glucagon suppression, and stimulation of insulin release after/ during meal consumption (a.k.a. the incretin effect). ${ }^{48}$ Therefore, grape consumption has the potential to improve glycemic control in humans with T2DM, assuming that total sugar consumption is not increased.

As mentioned in the results, the acute and long-term feeding of grape powder to prediabetic and normoglycemic mice did not result in improved glycemic control after GTT and ITT challenges and also did not lower body weight compared to sugar-matched control. Given the results of Study 1, a more focused approach to studying the effects of long term grape consumption in mice with blunted GLP-1 signalling may show beneficial effects (assuming that grape constituents ameliorated the negative effects of GLP-1R antagonism by increasing GLP-1 secretion). Study 1 showed that grape powder has the ability to improve GLP-1 signalling under specific conditions. High fat feeding (diet-induced obesity C57BL/6J mouse model) is an effective method of inducing insulin resistance, impaired glucose tolerance, fasting hyperglycemia and obesity, ${ }^{49-51}$ which is a characteristic symptom of prediabetes. ${ }^{52}$ It has an advantage to monogenetic variant models when studying novel therapeutic dietary options as it is a closer representation of the complex nature of diet-induced obesity/prediabetes in humans, whereas monogenic models may only target one organ or metabolic pathwayp; ${ }^{49,53} \mathrm{C} 57 \mathrm{BL} /$ $6 \mathrm{~J}$ mice fed a high-fat diet compared with the same mice fed a standard fat diet (10\% kcal from fat) display significantly elevated insulin levels (hyperinsulinemia), significantly elevated blood glucose levels, and significantly reduced tolerance to oral glucose tolerance test. ${ }^{53} \mathrm{C} 57 \mathrm{BL} / 6 \mathrm{~J}$ mice display a "thrifty genotype" in which they appear to store fats extremely efficiently compared to carbohydrates, which makes a high-fat diet a good way to induce obesity in these mice. ${ }^{51}$ When this strain of mice is fed a high-fat diet, fat is the primary cause of inducing hyperglycemia and hyperinsulinemia. ${ }^{51}$ However, this model may not have induced defective GLP-1 signalling, which Study 1 suggests is the pathway through which grape constituents exert their effects. There are conflicting data regarding the effect of high fat feeding on GLP-1 secreting intestinal L-cells: 
one study found a decrease in the function of intestinal L-cells after 16 weeks of high fat feeding in mice, ${ }^{54}$ a conflicting study shows an increase in GLP-1 positive intestinal L-cells in obese humans and mice fed a high fat diet. ${ }^{55} \mathrm{~A}$ better model of defective GLP-1 signalling will allow for more focused exploration into the mechanisms and specific situations in which grape constituents may rectify defective GLP-1 signalling. Perhaps repeating these experiments with a GLP-1 receptor knockout mouse model would determine if grape constituents displayed their beneficial effect via ameliorating impaired GLP-1 signalling or via other pathways.

Additionally, the negative systemic effects of the high fat diet paired with the high sugar content of the grape powder may have overpowered any beneficial effects from the phenolics present in grape powder. A recent study from the McIntosh $\mathrm{lab}^{56}$ featured a similar study design to Study 4 of this paper; however, their mice were fed for 16 weeks with the treatment diets and they had several additional treatment diet groups including a high fat diet plus polyphenol extract treatment diet. This polyphenol extract (which did not have any sugars) was added to the high fat diet at 1.1 grams per 1000 grams; the polyphenol extract treatment resulted in significantly lower bodyweight and significantly improved glucose tolerance after 16 weeks of feeding as compared to the high fat diet plus grape powder treatment group. This indicates that the high sugar content of the grape powder is a significant factor in the development of impaired glucose tolerance as well as increased weight gain in this model.

We had planned to quantify serum feeding hormone levels (GLP-1, insulin) in all four studies; however, we discovered that it was not possible to collect sufficient amounts of blood via tail snip within the required time frames for these studies. Thus there are not complete insulin measurements for each of the studies.

It should be noted that the results of these experiments suggest that grapes as a whole exert these effects, as whole grape powder was employed to experimentally emulate whole grape consumption as opposed to grape extracts or fractions, which are less relevant and translatable to normal grape consumption. Additionally, one limitation of this study is that total GLP-1 ELISA kits were used to quantify serum GLP-1 levels; these kits measure both biologically active GLP-1 (7-36) as well as inactive GLP-1 (9-36) (which is the metabolite of active GLP-1 after the $2 \mathrm{~N}$-terminal amino acid residues are cleaved by DPP4). While serum levels of total GLP-1 do with the insulinotropic activity of GLP-1, the correlation is somewhat poor. Additionally, it is estimated that less than 25\% of GLP-1 leaves the gastrointestinal tract in the intact form. ${ }^{45}$ Therefore, it is difficult to quantify active GLP-1 in peripheral blood (particularly for mice, where small blood volumes are a limiting factor), and therefore we selected total GLP-1 as a measure of total GLP-1 secretion. Active GLP-1 ELISAs could be employed for more accurate quantification of biologically active GLP-1 in terms of insulinotropic activity. ${ }^{45,57}$ Accurate quantification of active GLP-1 and insulin response after consumption of grapes would be a valuable measure to include in future studies, potentially done in rats for larger blood volumes.

\section{Conclusions}

The present study reports a novel phenomenon: that grape powder consumption reversed dysfunctional GLP-1 signalling. However, the data also raise significant questions regarding the context in which grape consumption may effectively improve glycemic control. Grapes appears to have the potential to improve glucose homeostasis and overcome blunted GLP-1 signalling; however, more investigation is required in order to identify the precise biological mechanisms involved, determine the specific disease contexts in which this protection occurs, and create experimental conditions that can effectively mimic these disease contexts.

The benefits of grapes appear promising, and the hypotheses raised by the present study warrant further experiments. Perhaps we need to find a more appropriate model of impaired GLP-1 response/signalling in order to study this phenomenon. To test whether grape acts through other mechanisms to circumvent blunted GLP-1 response, we could employ GLP-1 and/ or GLP-1 receptor knockout mice. High-sugar diets may be employed to test the effects of long-term grape consumption in a different obesity model. Grape powder consumption may be extremely beneficial as insulinemia progresses after long-term high fat feeding, when increased incretin effect by GLP-1 may improve insulin secretion at the end of beta cell life.

\section{Acknowledgements}

Funding for this work was provided by the California Table Grape Commission (Fresno, CA) through the 2014-15 Health Research Grant Program. Funding was also provided, in part, by the Virginia Agricultural Experiment Station and the Hatch Program of the National Institute of Food and Agriculture (NIFA), U.S. Department of Agriculture. The authors wish to thank Mostafa Ali, VT Department of Human Nutrition, Foods and Exercise, for his assistance with murine procedures; additionally, the authors would like to thank Dr Hengjian Wang and Ken Hurley, VT Department of Food Science, for their assistance with proximate analysis of FDGP.

\section{References}

1 C. C. Cowie, K. F. Rust, E. S. Ford, M. S. Eberhardt, D. D. Byrd-Holt, C. Li, D. E. Williams, E. W. Gregg, K. E. Bainbridge, S. H. Saydah and L. S. Geiss, Full Accounting of Diabetes and Pre-Diabetes in the U.S. Population in 1988-1994 and 2005-2006, Diabetes Care, 2009, 32, 287294.

2 National Diabetes Fact Sheet, Centers for Disease Control, 2011.

3 D. H. Morris, K. Khunti, F. Achana, B. Srinivasan, L. J. Gray, M. J. Davies and D. Webb, Progression rates from HbA1c and other prediabetes definitions to type 2 diabetes: a meta-analysis, Diabetologia, 2013, 56, 1489-1493. 
4 L. Perreault, Q. Pan, K. J. Mather, K. E. Watson, R. F. Hamman, S. E. Kahn and G. Diabet Prevention Program Res, Effect of regression from prediabetes to normal glucose regulation on long-term reduction in diabetes risk: results from the Diabetes Prevention Program Outcomes Study, Lancet, 2012, 379, 2243-2251.

5 C. C. Chuang, W. Shen, H. Y. Chen, G. X. Xie, W. Jia, S. Chung and M. K. McIntosh, Differential Effects of Grape Powder and Its Extract on Glucose Tolerance and Chronic Inflammation in High-Fat-Fed Obese Mice, J. Agric. Food Chem., 2012, 60, 12458-12468.

6 Y. Ding, X. Q. Dai, Y. F. Jiang, Z. F. Zhang, L. Bao, Y. J. Li, F. Zhang, X. T. Ma, X. X. Cai, L. L. Jing, J. J. Gu and Y. Li, Grape seed proanthocyanidin extracts alleviate oxidative stress and ER stress in skeletal muscle of low-dose streptozotocin- and high-carbohydrate/high-fat diet-induced diabetic rats, Mol. Nutr. Food Res., 2013, 57, 365-369.

7 R. S. de Moura, G. F. da Costa, A. S. B. Moreira, E. F. Queiroz, D. D. Moreira, E. P. Garcia-Souza, A. C. Resende, A. S. Moura and M. T. Teixeira, Vitis vinifera L. grape skin extract activates the insulin-signalling cascade and reduces hyperglycaemia in alloxan-induced diabetic mice, J. Pharm. Pharmacol., 2012, 64, 268-276.

8 P. Kar, D. Laight, H. K. Rooprai, K. M. Shaw and M. Cummings, Effects of grape seed extract in Type 2 diabetic subjects at high cardiovascular risk: a double blind randomized placebo controlled trial examining metabolic markers, vascular tone, inflammation, oxidative stress and insulin sensitivity, Diabetic Med., 2009, 26, 526-531.

9 A. Castell-Auvi, L. Cedo, V. Pallares, M. Blay, M. Pinent and A. Ardevol, Grape seed procyanidins improve beta-cell functionality under lipotoxic conditions due to their lipid-lowering effect, J. Nutr. Biochem., 2013, 24, 948-953.

10 Y. Ding, Z. F. Zhang, X. Q. Dai, Y. F. Jiang, L. Bao, Y. J. Li and Y. Li, Grape seed proanthocyanidins ameliorate pancreatic beta-cell dysfunction and death in low-dose streptozotocin- and high-carbohydrate/high-fat diet-induced diabetic rats partially by regulating endoplasmic reticulum stress, Nutr. Metab., 2013, 10.

11 W. S. Aramsri Meeprom, W. Suwannaphet, S. Yibchokanun, S. Adisakwattana, M. Thounaojam, R. Jadeja, R. Devkar and A. Ramachandran, Grape seed extract supplementation prevents high-fructose diet-induced insulin resistance in rats by improving insulin and adiponectin signalling pathways, Br. J. Nutr., 2011, 106, 1173.

12 G. Montagut, C. Blade, M. Blay, J. Fernandez-Larrea, G. Pujadas, M. J. Salvado, L. Arola, M. Pinent and A. Ardevol, Effects of a grapeseed procyanidin extract (GSPE) on insulin resistance, J. Nutr. Biochem., 2010, 21, 961-967.

13 G. Montagut, S. Onnockx, M. Vaque, C. Blade, M. Blay, J. Fernandez-Larrea, G. Pujadas, M. J. Salvado, L. Arola, I. Pirson, A. Ardevol and M. Pinent, Oligomers of grapeseed procyanidin extract activate the insulin receptor and key targets of the insulin signaling pathway differently from insulin, J. Nutr. Biochem., 2010, 21, 476-481.
14 D. Pajuelo, S. Diaz, H. Quesada, A. Fernandez-Iglesias, M. Mulero, A. Arola-Arnal, M. J. Salvado, C. Blade and L. Arola, Acute administration of grape seed proanthocyanidin extract modulates energetic metabolism in skeletal muscle and BAT mitochondria, J. Agric. Food Chem., 2011, 59, 4279-4287.

15 D. Pajuelo, A. Fernandez-Iglesias, S. Diaz, H. Quesada, A. Arola-Arnal, C. Blade, J. Salvado and L. Arola, Improvement of mitochondrial function in muscle of genetically obese rats after chronic supplementation with proanthocyanidins, J. Agric. Food Chem., 2011, 59, 8491-8498.

16 N. Gonzalez-Abuin, N. Martinez-Micaelo, M. Margalef, M. Blay, A. Arola-Arnal, B. Muguerza, A. Ardevol and M. Pinent, A grape seed extract increases active glucagonlike peptide-1 levels after an oral glucose load in rats, Food Funct., 2014, 5, 2357-2364.

17 Y. Yamashita, M. Okabe, M. Natsume and H. Ashida, Cinnamtannin A2, a Tetrameric Procyanidin, Increases GLP-1 and Insulin Secretion in Mice, Biosci., Biotechnol., Biochem., 2013, 77, 888-891.

18 N. Gonzalez-Abuin, N. Martinez-Micaelo, M. Blay, G. Pujadas, S. Garcia-Vallve, M. Pinent and A. Ardevol, Grape Seed-Derived Procyanidins Decrease Dipeptidyl-peptidase 4 Activity and Expression, J. Agric. Food Chem., 2012, 60, 9055-9061.

19 N. Gonzalez-Abuin, N. Martinez-Micaelo, M. Blay, A. Ardevol and M. Pinent, Grape-Seed Procyanidins Prevent the Cafeteria-Diet-Induced Decrease of Glucagon-Like Peptide-1 Production, J. Agric. Food Chem., 2014, 62, 10661072.

20 Y.-S. Lin, C.-R. Chen, W.-H. Wu, C.-L. Wen, C.-I. Chang and W.-C. Hou, Anti- $\alpha$-glucosidase and Anti-dipeptidyl Peptidase-IV Activities of Extracts and Purified Compounds from Vitis thunbergii var. taiwaniana, J. Agric. Food Chem., 2015, 63, 6393-6401.

21 J. Serrano, A. Casanova-Marti, K. Gil-Cardoso, M. T. Blay, X. Terra, M. Pinent and A. Ardevol, Acutely administered grape-seed proanthocyanidin extract acts as a satiating agent, Food Funct., 2016, 7, 483-490.

22 P. Marchetti, R. Lupi, M. Bugliani, C. L. Kirkpatrick, G. Sebastiani, F. A. Grieco, S. Guerra, V. D’Aleo, S. Piro, L. Marselli, U. Boggi, F. Filipponi, L. Tinti, L. Salvini, C. B. Wollheim, F. Purrello and F. Dotta, A local glucagonlike peptide 1 (GLP-1) system in human pancreatic islets, Diabetologia, 2012, 55, 3262-3272.

23 S. Vasu, R. C. Moffett, N. H. McClenaghan and P. R. Flatt, Differential molecular and cellular responses of GLP-1 secreting L-cells and pancreatic alpha cells to glucotoxicity and lipotoxicity, Exp. Cell Res., 2015, 336, 100-108.

24 J. G. Barrera, D. A. Sandoval, D. A. D'Alessio and R. J. Seeley, GLP-1 and energy balance: an integrated model of short-term and long-term control, Nat. Rev. Endocrinol., 2011, 7, 507-516.

25 J.-P. Gutzwiller, J. Drewe, B. Göke, H. Schmidt, B. Rohrer, J. Lareida and C. Beglinger, Glucagon-like peptide-1 promotes satiety and reduces food intake in patients with dia- 
betes mellitus type 2, Am. J. Physiol.: Regul., Integr. Comp. Physiol., 1999, 276, R1541-R1544.

26 L. B. Knudsen, D. Kiel, M. Teng, C. Behrens, D. Bhumralkar, J. T. Kodra, J. J. Holst, C. B. Jeppesen, M. D. Johnson, J. C. de Jong, A. S. Jorgensen, T. Kercher, J. Kostrowicki, P. Madsen, P. H. Olesen, J. S. Petersen, F. Poulsen, U. G. Sidelmann, J. Sturis, L. Truesdale, J. May and J. Lau, Small-molecule agonists for the glucagon-like peptide 1 receptor, Proc. Natl. Acad. Sci. U. S. A., 2007, 104, 937-942.

27 N. González-Abuín, N. Martínez-Micaelo, M. Blay, B. D. Green, M. Pinent and A. Ardévol, Grape-seed procyanidins modulate cellular membrane potential and nutrient-induced GLP-1 secretion in STC-1 cells, Am. J. Physiol.: Cell Physiol., 2014, 306, C485-C492.

28 J. L. Donovan, C. Manach, L. Rios, C. Morand, A. Scalbert and C. Remesy, Procyanidins are not bioavailable in rats fed a single meal containing a grapeseed extract or the procyanidin dimer B-3, Br. J. Nutr., 2002, 87, 299-306.

29 A. Scheen, Dipeptidylpeptidase-4 Inhibitors (Gliptins), Clin. Pharmacokinet., 2010, 49, 573-588.

30 B. Collins, J. Hoffman, K. Martinez, M. Grace, M. A. Lila, C. Cockrell, A. Nadimpalli, E. Chang, C. C. Chuang, W. Zhong, J. Mackert, W. Shen, P. Cooney, R. Hopkins and M. McIntosh, A polyphenol-rich fraction obtained from table grapes decreases adiposity, insulin resistance and markers of inflammation and impacts gut microbiota in high-fat-fed mice, J. Nutr. Biochem., 2016, 31, 150-165.

31 M. Hanausek, E. Spears, Z. Walaszek, M. C. Kowalczyk, P. Kowalczyk, C. Wendel and T. J. Slaga, Inhibition of Murine Skin Carcinogenesis by Freeze-Dried Grape Powder and Other Grape-Derived Major Antioxidants, Nutr. Cancer, 2011, 63, 28-38.

32 Y. Xu, V. I. Khaoustov, H. Wang, J. Yu, F. Tabassam and B. Yoffe, Freeze-dried grape powder attenuates mitochondria- and oxidative stress-mediated apoptosis in liver cells, J. Agric. Food Chem., 2009, 57, 9324.

33 B. Fuhrman, N. Volkova, R. Coleman and M. Aviram, Grape powder polyphenols attenuate atherosclerosis development in apolipoprotein E deficient (E-O) mice and reduce macrophage atherogenicity, J. Nutr., 2005, 135, 722-728.

34 C.-C. Chuang, W. Shen, H. Chen, G. Xie, W. Jia, S. Chung and M. K. McIntosh, Differential Effects of Grape Powder and Its Extract on Glucose Tolerance and Chronic Inflammation in High-Fat-Fed Obese Mice, J. Agric. Food Chem., 2012, 60, 12458-12468.

35 N. Solanki, I. Alkadhi, F. Atrooz, G. Patki and S. Salim, Grape powder prevents cognitive, behavioral, and biochemical impairments in a rat model of posttraumatic stress disorder, Nutr. Res., 2015, 35, 65-75.

36 R. L. Prior, E. Fan, H. Ji, A. Howell, C. Nio, M. J. Payne and J. Reed, Multi-laboratory validation of a standard method for quantifying proanthocyanidins in cranberry powders, J. Sci. Food Agric., 2010, 90, 1473-1478.

37 V. L. Singleton, R. Orthofer and R. M. Lamuela-Raventós, in Methods in Enzymology, ed. P. Lester, Academic Press, 1999, vol. 299, pp. 152-178.
38 J. Lee, R. W. Durst and R. E. Wrolstad, Determination of total monomeric anthocyanin pigment content of fruit juices, beverages, natural colorants, and wines by the $\mathrm{pH}$ differential method: Collaborative study, J. AOAC Int., 2005, 88, 1269-1278.

39 C. T. G. Commission, 2014-15 Health Research Grants, Grape Powder Usage Guidelines, 2013.

40 B. Thorens, A. Porret, L. Buhler, S. P. Deng, P. Morel and C. Widmann, Cloning and functional expression of the human islet GLP-1 receptor - demonstration that Exendin-4 is an agonist and Exendin-(9-39) an antagonist of the receptor, Diabetes, 1993, 42, 1678-1682.

41 V. Serre, W. Dolci, E. Schaerer, L. Scrocchi, D. Drucker, S. Efrat and B. Thorens, Exendin-(9-39) is an inverse agonist of the murine glucagon-like peptide- 1 receptor: Implications for basal intracellular cyclic adenosine 3 ',5 '-monophosphate levels and beta-cell glucose competence, Endocrinology, 1998, 139, 4448-4454.

42 J. Schirra, K. Sturm, P. Leicht and R. Arnold, xF, B. ke and M. Katschinski, Exendin(9-39)amide is an antagonist of glucagon-like peptide-1(7-36)amide in humans, J. Clin. Invest., 1998, 101, 1421-1430.

43 V. A. Gault, F. P. M. O'Harte, P. Harriott, M. H. Mooney, B. D. Green and P. R. Flatt, Effects of the novel (Pro3)GIP antagonist and exendin(9-39)amide on GIP- and GLP-1induced cyclic AMP generation, insulin secretion and postprandial insulin release in obese diabetic (ob/ob) mice: evidence that GIP is the major physiological incretin, Diabetologia, 2003, 46, 222-230.

44 S. Reagan-Shaw, M. Nihal and N. Ahmad, Dose translation from animal to human studies revisited, FASEB J., 2008, 22, 659-661.

45 J. J. Holst, The Physiology of Glucagon-like Peptide 1, 2007.

46 M. B. Toft-Nielsen, M. B. Damholt, S. Madsbad, L. M. Hilsted, T. E. Hughes, B. K. Michelsen and J. J. Holst, Determinants of the impaired secretion of glucagon-like peptide- 1 in type 2 diabetic patients, J. Clin. Endocrinol. Metab., 2001, 86, 3717-3723.

47 L. A. Scrocchi, T. J. Brown, N. MacLusky, P. L. Brubaker, A. B. Auerbach, A. L. Joyner and D. J. Drucker, Glucose intolerance but normal satiety in mice with a null mutation in the glucagon-like peptide 1 receptor gene, Nat. Med., 1996, 2, 1254-1258.

48 L. A. Scrocchi, B. A. Marshall, S. M. Cook, P. L. Brubaker and D. J. Drucker, Identification of glucagon-like peptide 1 (GLP-1) actions essential for glucose homeostasis in mice with disruption of GLP-1 receptor signaling, Diabetes, 1998, 47, 632-639.

49 T. Y. Reuter, Diet-induced models for obesity and type 2 diabetes, Drug Discovery Today: Dis. Models, 2007, 4, 3-8.

50 R. S. Surwit, C. M. Kuhn, C. Cochrane, J. A. McCubbin and M. N. Feinglos, Diet-induced type II diabetes in C57BL/6J mice, Diabetes, 1988, 37, 1163-1167.

51 R. S. Surwit, M. N. Feinglos, J. Rodin, A. Sutherland, A. E. Petro, E. C. Opara, C. M. Kuhn and M. Rebuffe-Scrive, 
Differential effects of fat and sucrose on the development of obesity and diabetes in C57BL/6J and A J mice, Metabolism, 1995, 44, 645-651.

52 M. S. Winzell and B. Ahrén, The High-Fat Diet-Fed Mouse: A Model for Studying Mechanisms and Treatment of Impaired Glucose Tolerance and Type 2 Diabetes, Diabetes, 2004, 53, S215-S219.

53 C. Gallou-Kabani, A. Vige, M. S. Gross, J. P. Rabes, C. Boileau, C. Larue-Achagiotis, D. Tome, J. P. Jais and C. Junien, C57BL/6J and A/J mice fed a high-fat diet delineate components of metabolic syndrome, Obesity, 2007, 15, 1996-2005.

54 P. Richards, R. Pais, A. M. Habib, C. A. Brighton, G. S. Yeo, F. Reimann and F. M. Gribble, High fat diet impairs the function of glucagon-like peptide-1 producing L-cells, Peptides, 2016, 77, 21-27.
55 T. Aranias, A. Grosfeld, C. Poitou, A. A. Omar, M. Le Gall, S. Miquel, K. Garbin, A. Ribeiro, J. L. Bouillot, A. Bado, E. Brot-Laroche, K. Clement, A. Leturque, S. Guilmeau and P. Serradas, Lipid-rich diet enhances L-cell density in obese subjects and in mice through improved L-cell differentiation, J. Nutr. Sci., 2015, 4, e22.

56 B. Collins, J. Hoffman, K. Martinez, M. Grace, M. A. Lila, C. Cockrell, A. Nadimpalli, E. Chang, C.-C. Chuang, W. Zhong, J. Mackert, W. Shen, P. Cooney, R. Hopkins and M. McIntosh, A polyphenol-rich fraction obtained from table grapes decreases adiposity, insulin resistance and markers of inflammation and impacts gut microbiota in high-fat-fed mice, J. Nutr. Biochem., 2016, 31, 150-165.

57 A. C. Heijboer, A. Frans, M. Lomecky and M. A. Blankenstein, Analysis of glucagon-like peptide 1; what to measure?, Clin. Chim. Acta, 2011, 412, 1191-1194. 